\title{
DÜBLIN
}

Technological University Dublin

ARROW@TU Dublin

\section{Impact of Plasma Jet Geometry on Residence Times of Radical Species}

James Lalor

Technological University Dublin

Laurence Scally

Technological University Dublin

Patrick Cullen

Technological University Dublin, pj.cullen@tudublin.ie

See next page for additional authors

Follow this and additional works at: https://arrow.tudublin.ie/schfsehart

Part of the Engineering Commons

\section{Recommended Citation}

Lalor, J., Scally, L. \& Cullen, P.J. (2018). Impact of plasma jet geometry on residence times of radical species. Journal of Vacuum Science and Technology, vol. 36, no. 3. doi.org/10.1116/1.5022294

This Article is brought to you for free and open access by the School of Food Science and Environmental Health at ARROW@TU Dublin. It has been accepted for inclusion in Articles by an authorized administrator of ARROW@TU Dublin. For more information, please contact arrow.admin@tudublin.ie, aisling.coyne@tudublin.ie, gerard.connolly@tudublin.ie.

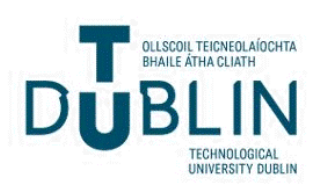




\section{Authors}

James Lalor, Laurence Scally, Patrick Cullen, and Vladimir Milosavljevic

This article is available at ARROW@TU Dublin: https://arrow.tudublin.ie/schfsehart/305 


\title{
Impact of plasma jet geometry on residence times of radical species
}

\author{
James Lalor \\ BioPlasma Research Group, Dublin Institute of Technology, Sackville Place, Dublin 1, Dublin, Ireland and School \\ of Mechanical and Design Engineering, Dublin Institute of Technology, Bolton Street, Dublin 1, Dublin, Ireland \\ Laurence Scally \\ BioPlasma Research Group, Dublin Institute of Technology, Sackville Place, Dublin 1, Dublin, Ireland \\ Patrick J. Cullen ${ }^{\text {a) }}$ \\ BioPlasma Research Group, Dublin Institute of Technology, Sackville Place, Dublin 1, Dublin, Ireland \\ and Department of Chemical and Environmental Engineering, University of Nottingham, NG7 2RD \\ Nottingham, United Kingdom \\ Vladimir Milosavljevićb) \\ BioPlasma Research Group, Dublin Institute of Technology, Sackville Place, Dublin 1, Dublin, Ireland \\ and Faculty of Physics, University of Belgrade, P.O.B. 368, Belgrade 11000, Serbia
}

(Received 12 January 2018; accepted 20 April 2018; published 8 May 2018)

\begin{abstract}
Numerous electrode geometries and power supplies, both commercial and in-house, have been employed for the generation of low-temperature atmospheric plasma jets. In this work, the development and operation of a 12 jet nonthermal atmospheric plasma system is presented. The study is based on optical spectroscopy as a diagnostic method due to its nonintrusive nature. A key focus of this study was the material selection (conductive and nonconductive), with several polymers screened for the jet design leading to polyacetal as the choice material. Their results are compared with other atmospheric plasma jet systems. The results show a significant increase in residence time and the spatial homogeneity for ambient air's main species, including: $\mathrm{OH}, \mathrm{O} \mathrm{I}, \mathrm{O}_{2}, \mathrm{O}_{3}, \mathrm{~N}_{2}$, and $\mathrm{N}_{2}{ }^{+}$. Their densities are studied with respect to treatment time, distance, duty cycle, and discharge frequency, as well as the jets' carrier gas chemistries (argon and helium). For their plasma jet system, the bulk of the chemical reactions occur in the surrounding atmosphere and not in the jet nozzle, which is different from most other plasma jet systems. The electron energy distribution function, for the given chemistries, is also reported. Published by the AVS. https://doi.org/10.1116/1.5022294
\end{abstract}

\section{INTRODUCTION}

Plasma sources have the ability to manipulate gasses and materials. At an atomic level, they have facilitated significant advancement in science and technology, such as semiconductors, thin films and biomaterials. Most atmospheric pressure nonthermal plasma systems have the ability to generate high concentrations of reactive species capable of uniformly removing or depositing material at rates of up to $10 \mu \mathrm{m} / \mathrm{min}$, with both submicron accuracy and at temperatures low enough not to damage the substrates.

When considering practical applications, atmospheric plasmas offer two valuable features. First, they offer temperature and energy densities greater than those produced by ordinary chemical means. In thermal plasmas at atmospheric pressure, such as transfer arcs and torches, the electron and neutral temperatures exceed $3000^{\circ} \mathrm{C}$ and the densities of charged species are in the range of $10^{16}-10^{19} \mathrm{~cm}^{3}$. Due to the high gas temperature, metallurgy remains the principle application for these plasmas. However, there are different ways of generating lowtemperature plasmas at atmospheric pressures. Low-temperature atmospheric pressure plasmas have achieved significant developments over the past decade. Established techniques include arc discharges, corona discharge, dielectric barrier discharge, and plasma jets. Atmospheric pressure plasma jets (APPJs) can

\footnotetext{
${ }^{a)}$ Electronic mail: pjcullen@dit.ie

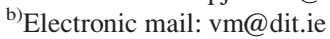

be configured to offer a nonthermal, versatile plasma treatment sources. ${ }^{1}$ These plasma sources have now been used for multiple applications, including surface modification. ${ }^{2,3}$ They can be generated using relatively simple designs and the associated low gas kinetic temperature properties are of particular interest to thermally sensitive surfaces including those found in biology and medicine.

A large range of electrode geometries and power supplies have been used for low-temperature atmospheric plasma jet generation. Early designs focused on plasma generation with expensive inert gas chemistries such as helium or argon. To address these limitations a robust atmospheric, multigas (including molecular gases) plasma jet was developed, ${ }^{4}$ which is similar to a glow discharge and it is generated by highvoltage $(2-3 \mathrm{kV})$ AC power supply $(50 \mathrm{~Hz}$ to $16 \mathrm{kHz})$. The plasma gas has a relatively low afterglow temperature, and consequently there is a reduced risk of thermal damage to the target material. As a result of these characteristics, this plasma source has been used in hydrophilization of polyimide films and material sterilization. There are also multiple types of atmospheric pressure nonthermal plasma jets where noble gases are mixed with a small percentage of reactive gases. ${ }^{5}$ Although APPJs have seen many applications employing single jet configurations, complex challenges associated with multijet arrays exist. First, the supply gas and power to operate several APPJs requires a distribution network designed to deliver uniform parameters. ${ }^{6}$ Second, when individual jets 
operate cooperatively, through individual ballasting and tailoring of the power supply and the gas flow, they do so in a localized manner with each jet coupling separately to downstream substrates. ${ }^{6,7}$ In multijet APPJs, mutual electric and hydrodynamic interactions occur, which result in the divergence or the extinguishing of individual jets or alternatively the merging of individual jets into a single jet much smaller than the diameter of the jet array system. Although solutions have been suggested, current systems have limitations associated with nonuniformity. In general, APPJs are not challenging to construct, and as a result many different jet configurations have been reported. One common type of APPJ employs a coaxial electrode structure with the electric field being largely in the radial direction and the feed gas flowing in the axial direction. ${ }^{8-10}$ This configuration is termed "cross-field," due to its electric field and its flow field being perpendicular to each other. Another common jet configuration employs a powered electrode wrapped around a hollow dielectric tube through which the feed gas flows axially. ${ }^{11,12}$ As the flow field and the electric field are parallel, these types of APPJs are referred to as "linear-field" devices. Despite the scale of their applications, there is considerable ambiguity as to their relative merits for materials processing, thus compromising the value of many application-focused studies. This ambiguity also highlights an important knowledge gap in APPJ physics and chemistry. ${ }^{8}$

There are a number of publications reporting on atmospheric pressure plasma jets and their ability to produce reactive species. ${ }^{13}$ In order to increase the effects and to control the production of reactive species, an understanding of the interaction between the plasma, the selected gas chemistry, and the gas flow is of major importance as well as the influence of ambient air to overall plasma chemistry. ${ }^{14,15}$ The plasma is also reported to be enhanced by the transition from a laminar to a turbulent flow regime. ${ }^{16}$ Two hypotheses are proposed: thermal effects associated with the gas heating and electro hydrodynamic forces due to ion momentum transfers to neutrals, with both found with helium flows and could acquire forward momentum with the plasma. ${ }^{17}$ For multiple helium plasma jets, it is observed that they cause an earlier onset of turbulence and they emphasize more on the role of thermal effects. ${ }^{18}$ Through numerical simulation of an argon plasma jet, Shao et al. ${ }^{19}$ found that adding an electrostatic force facilitated a forward momentum in the flow, which was in agreement with their experimental observations. ${ }^{19}$ They also emphasized the role of the argon mole fraction variation in the flow which has been reported to influence plasma plume length in the case of a helium plasma jet. ${ }^{20}$ In several studies, the onset of a turbulent flow induced by the plasma has been associated with a reduction of the plasma plume length, due to a higher concentration of air mixing in the working flow. ${ }^{21}$ Furthermore, it was also shown that a given plasma plume pattern is influenced by both the flow rate and the pulse repetition rate. ${ }^{22}$

Due to the low ionization energy required for ambient air species, gases such as helium or argon are used extensively as carrier gases to generate plasmas. However, these combinations are capable of producing reactive oxygen and nitrogen species. The nature, quantity and role of the plasma species generated depends on the type of plasma device used and the carrier gas composition. ${ }^{5,23-25}$ The plasma radicals studied in this work are as follows: $\mathrm{N}_{2}$ (second positive system), $\mathrm{N}_{2}{ }^{+}$ (first negative system), O I (transition 3p-3s), $\mathrm{O}_{2}$ (atmospheric band), $\mathrm{O}_{3}$ (Hartley band), $\mathrm{OH}$ (UV band), He I (transitions 3s$2 \mathrm{p}, 3 \mathrm{~d}-2 \mathrm{p}$ and $3 \mathrm{p}-2 \mathrm{~s}$ ), and $\mathrm{Ar}$ I (transitions $4 \mathrm{p}^{\prime}-4 \mathrm{~s}^{\prime}$ and $4 \mathrm{p}-4 \mathrm{~s}$ ). The main objectives of this work are as follows: the design and characterization of a new multijet plasma system, as well as to explore the temporal and spatial production of the radicals mentioned above. The measurement and control of these radicals could be used for the purpose of food sterilization, the treatment of packaging surfaces and biological samples. Oxygen species are particularly important for such applications with the observed antimicrobial effects linked to several mechanisms, ${ }^{26}$ including reactive oxygen species. Any shift in the electron energy distribution function (EEDF), as a function of the external parameters, in the helium and/or argon plasmas are monitored. This study also includes a mapping of the plasma spectral intensity distribution as a function of the external parameters for: a single open air plasma jet system, a multiaxial open air 12 jet system and the 12 jet plasma system housed within an open tunnel configuration. The 12 jet tunnel system is presented for the first time and it is a complex three dimensional shape that can be used for an in line processing of bulk materials with complex geometries.

\section{EXPERIMENTAL APPARATUS AND METHOD}

The study and diagnostics of plasma includes: optical emission spectroscopy (OES), optical absorption spectroscopy (OAS), and phase resolved optical emission spectroscopy (PROES). These optical diagnostic methods are applied for the temporal and spatial measurement of the plasma reactive species. Due to its simplicity, optical spectroscopy is commonly used for the measurement and real time monitoring of plasma radicals and plasma kinetic processes. For comparison purposes, the absolute spectral intensity measurement of the atomic lines and molecular bands associated with helium, argon, oxygen, and nitrogen are included.

\section{A. Plasma radicals}

The most important species in this work is oxygen and is presented in atomic and molecular forms. The excited oxygen species are created from interactions with ambient air, since the main feeder gas is argon and/or helium. Therefore, the noble gases have an important role in such plasma discharges. Spectroscopic data includes the following atomic argon ( $\mathrm{Ar} \mathrm{I})$ spectral line emissions: ${ }^{27} 750.387 \mathrm{~nm}\left({ }^{1} \mathrm{~S}_{0} \rightarrow{ }^{1} \mathrm{P}_{1}\right), 763.511 \mathrm{~nm}$ $\left({ }^{3} \mathrm{D}_{2} \rightarrow{ }^{3} \mathrm{P}_{2}\right), 794.818 \mathrm{~nm}\left({ }^{3} \mathrm{P}_{1} \rightarrow{ }^{3} \mathrm{P}_{0}\right), 801.479 \mathrm{~nm}\left({ }^{3} \mathrm{D}_{2} \rightarrow{ }^{3} \mathrm{P}_{2}\right)$, $811.531 \mathrm{~nm}\left({ }^{3} \mathrm{D}_{3} \rightarrow{ }^{3} \mathrm{P}_{2}\right)$, and $842.465\left({ }^{3} \mathrm{D}_{2} \rightarrow{ }^{3} \mathrm{P}_{1}\right)$. The brackets show the transitions based on LS (Russell-Saunders or orbital angular momentum-L and spin angular momentum-S) notation. Two of these six Ar I spectral lines are particularly important. The spectral line at $750.387 \mathrm{~nm}(\mathrm{Ar} 750)$ is created by direct electron excitation from the ground level and could be used as a representative of the ion density in the plasma. The upper energy level of Ar750 is about $13.5 \mathrm{eV}$ with a mean lifetime of $22 \mathrm{~ns}$. The other spectral line is $811.531 \mathrm{~nm}$ (Ar811) and is the strongest transition that ends on the argon metastable energy level. It 
has a long lifetime, and can be used for monitoring the metastable argon atom. This line is sensitive to low-energy electrons. In this work, three atomic helium (He I) spectral emission lines ${ }^{27}$ are recoded: $706.519 \mathrm{~nm} \quad\left(3 \mathrm{~s}^{3} \mathrm{~S}_{1} \rightarrow 2 \mathrm{p}^{3} \mathrm{P}^{\circ}{ }_{1,2}\right), \quad 587.562 \mathrm{~nm}$ $\left(3 \mathrm{~d}^{3} \mathrm{D}_{1,2,3} \rightarrow 2 \mathrm{p}^{3} \mathrm{P}_{1,2}^{\circ}\right)$, and $388.865 \mathrm{~nm}\left(3 \mathrm{p}^{3} \mathrm{P}^{\circ}{ }_{1,2} \rightarrow 2 \mathrm{~s}^{3} \mathrm{~S}_{1}\right)$. All the recorded helium lines belong to helium triplet states, the triplet energy levels lie at a lower state than the singlet energy levels, and $2 s^{3} S_{1}(19.8 \mathrm{eV})$ is the helium metastable level since transition from this level to the ground state is forbidden due to the LS rule (the angular quantum number $= \pm 1$ and the spin quantum number $=0)$. The spectral line at $706.519 \mathrm{~nm}(\mathrm{He} 706)$ is also significant for plasma diagnostics. Namely, the upper energy level $3 \mathrm{~s}^{3} \mathrm{~S}_{1}(22.7 \mathrm{eV})$ populates by direct electron excitation from the ground level; consequently, this spectral emission is sensitive to high-energy electrons. Helium also has an important role in the creation of molecular nitrogen spectral emissions. The nitrogen molecule has a number of electronic excitation states below the argon and helium metastable energy levels. The noble gas metastable energy levels act as an energy storage device, since their lifetime is several orders of magnitude longer that the ordinary atomic/molecular energy levels. In this work the strongest $\mathrm{N}_{2}$ emission is the second positive system $^{28}$ $\left(\mathrm{C}^{3} \Pi^{+}{ }_{\mathrm{u}} \rightarrow \mathrm{B}^{3} \Pi^{+}{ }_{\mathrm{g}}\right)$, with energies ranging from 9 to $11.5 \mathrm{eV}$. The recorded $\mathrm{N}_{2}$ vibration band-heads, $\mathrm{v}^{\prime \prime}=0,1,2,3 \rightarrow \mathrm{v}^{\prime}=0$ (vibrational quantum numbers) are located at wavelengths 337 , 358,380 , and $406 \mathrm{~nm}$, respectively. Apart from this nitrogen spectral emission, a spectral emission of the molecular nitrogen ion $\left(\mathrm{N}_{2}{ }^{+}\right)$from the first negative system ${ }^{28}\left(\mathrm{~B}^{2} \Sigma^{+}{ }_{\mathrm{u}} \rightarrow \mathrm{X}^{2} \Sigma^{+}{ }_{\mathrm{g}}\right)$ is also observed. Namely, the single $\mathrm{N}_{2}{ }^{+}$band-head at $\lambda=391 \mathrm{~nm}$ $\left(\mathrm{v}^{\prime \prime}=0 \rightarrow \mathrm{v}^{\prime}=0\right)$ is recorded. The $\mathrm{B}^{2} \Sigma_{\mathrm{u}}$ state has a high energy of $19 \mathrm{eV}$, and high-energy electrons are the main contributors to molecular ion production, as well as helium metastable atoms (the argon metastable energy levels are below $19 \mathrm{eV}$ ). Therefore, the $\mathrm{N}_{2}$ spectral emission is much higher in helium plasma than argon, despite the energy similarity between $\mathrm{Ar}$ I and $\mathrm{N}_{2}$. Namely, molecular recombination of $\mathrm{N}_{2}{ }^{+}$is very efficient process for the population of the $\mathrm{N}_{2}\left(\mathrm{C}^{3} \Pi_{\mathrm{u}}\right)$ state by

$$
\begin{aligned}
& \text { step 1: } \mathrm{He}\left(2 \mathrm{~s}^{3} \mathrm{~S}_{1}\right)+\mathrm{N}_{2}(\mathrm{X}) \\
& \quad \rightarrow \mathrm{N}_{2}{ }^{+}\left(\mathrm{B}^{2} \Sigma_{\mathrm{u}}\right)+\mathrm{He}\left(1 \mathrm{~s}^{2} \mathrm{~S}_{0}\right)+\mathrm{e}^{-} ; \\
& \text {step 2: } \mathrm{N}_{2}{ }^{+}\left(\mathrm{B}^{2} \Sigma_{\mathrm{u}}\right)+\mathrm{e}^{-} \rightarrow \mathrm{N}_{2}\left(\mathrm{C}^{3} \Pi_{\mathrm{u}}\right) .
\end{aligned}
$$

In this work, atomic oxygen (O I) spectral emissions from two triplets ${ }^{27}$ are represented. The OI $\left({ }^{5} \mathrm{P}_{3,2,1} \rightarrow{ }^{5} \mathrm{~S}_{2}^{\mathrm{o}}\right)$ at $777 \mathrm{~nm}$ and O I $\left({ }^{3} \mathrm{P}_{2,1,0} \rightarrow{ }^{3} \mathrm{~S}^{\mathrm{o}}\right)$ at $845 \mathrm{~nm}$ are recorded, with the oxygen triplet $\mathrm{O} 777$ having the strongest oxygen spectral emission. The OI $\left({ }^{5} \mathrm{P}_{3,2,1}\right)$ energy of $10.7 \mathrm{eV}$ is very close to the energy of the $\mathrm{N}_{2}\left(\mathrm{C}^{3} \Pi_{\mathrm{u}}\right)$ level which facilitates the possibility of physical interaction between oxygen and nitrogen, apart from the expected chemical interaction between them. The lifetime of the O I $3 p^{5} \mathrm{P}$ state is about $30 \mathrm{~ns}$. In this experiment, the spectral emission of molecular oxygen $\left(\mathrm{O}_{2}\right)$ was very weak. Therefore, the $\mathrm{O}_{2}$ absorption atmospheric band ${ }^{28}$ at $762 \mathrm{~nm}$ (a band center), which belongs to a vibrational subtransition of the $\mathrm{X}^{3} \Sigma^{-} \mathrm{g} \rightarrow \mathrm{b}^{1} \Sigma^{+}{ }_{\mathrm{g}}$ magnetic dipole transition, is recorded. This band center has a spectroscopic notation of R13Q14. The $\mathrm{O}_{2}$ dissociative excitation has a documented impact on the creation of $\mathrm{O} 777$ and $\mathrm{O} 845$ spectral emission. That process is more significant for $\mathrm{O} 777$ than $\mathrm{O} 845$ due to the higher cross section for excitation by molecular dissociation. The excitation process occurs with the oxygen molecule by physical quenching, and only results in the deactivation of singlet oxygen to its ground state, with no oxygen consumption or product formation. The last two products of the electrical discharges in this experiment were the hydroxyl radicals $(\mathrm{OH})$ and ozone $\left(\mathrm{O}_{3}\right)$. The $\mathrm{OH}$ $\left(\mathrm{A}^{2} \Sigma^{+} \rightarrow \mathrm{X}^{2} \Pi\right)$ UV band is recorded, this spectral emission lies around $310 \mathrm{~nm}$, with four heads (two R and two Q) and all of them degraded to the red. The most intensive $\mathrm{OH}\left(\mathrm{v}^{\prime \prime}\right.$ $\left.=0 \rightarrow \mathrm{v}^{\prime}=0\right)$ spectral emission is $\left(\mathrm{Q}_{1}\right)$ at $309 \mathrm{~nm}(\mathrm{OH} 309)$, which is well separated from the other spectral emissions. From all the recorded species in this experiment, $\mathrm{O}_{3}$ is the most powerful oxidant and is currently used for food and material sterilization. $\mathrm{O}_{3}$ has molecular bands in the $200-430 \mathrm{~nm}$ spectral range, and in this experiment the transition of the Hartley band $\left(\mathrm{X}^{1} \mathrm{~A}_{1} \rightarrow 1^{1} \mathrm{~B}_{2}\right)$ is recorded by absorption spectroscopy with the band-head at $254 \mathrm{~nm}$. In most plasma discharges, oxygen dissociation by electron impact with the subsequent threebody recombination of atomic and molecular oxygen would produce $\mathrm{O}_{3}$ molecules. Therefore, $\mathrm{O}_{3}$ production is energy demanding with the $\mathrm{O}_{3}$ molecule being very sensitive to temperature. Thus, ozone density in plasma discharges would depend on many competitive kinetic processes.

\section{B. Experimental setup}

A schematic diagram of the experimental apparatus is shown in Fig. 1.

We have customized this power source (see the Appendix for more details about the power source). The customized power source has a power of $2 \mathrm{~kW}$, a high frequency power driver from 20 to $100 \mathrm{kHz}$, a peak to peak voltage up to $40 \mathrm{kV}$ (load dependent) and a duty cycle control from $10 \%$ to $90 \%$ (this control has an impact on the $\mathrm{Q}$ factor, with the $\mathrm{Q}$ values increase an energy loss decreases). The customized oil filled transformer is tailor-made for the particular range of output (load) capacities $(10 \mathrm{pF}-20 \mathrm{nF})$. The variac is used for input voltage control.

Electrical current and high voltage (HV) are measured by electrical current (6) and voltage (7) probes, respectively. This setup does not have a matching network, and consequently to estimate the maximum power dissipated in the jets system, the voltage and current measurements are used. The maximum power delivered to the 12-jets plasma system was $450 \mathrm{~W}$.

The plasma jet design (12 in-house made jets) is shown in Fig. 2. The central HV electrode is a pin and the ground electrode has a ring shape. It composes of concentric cylindrical elements. The assembled unit exists within a cylindrical space of length $100 \mathrm{~mm}$ and diameter $45 \mathrm{~mm}$. The central nonconductive cylinder provides three functions. First, it suspends the central single pin HV electrode in a secure and insulated position. Second, it is the dielectric barrier component of the plasma source. Finally, it provides the ability to have a controlled gas flow across the electric field through the polar array of holes drilled longitudinally through it.

The gas flow through the jet starts from the top of the central electrode and expands to the surrounding air outside the 


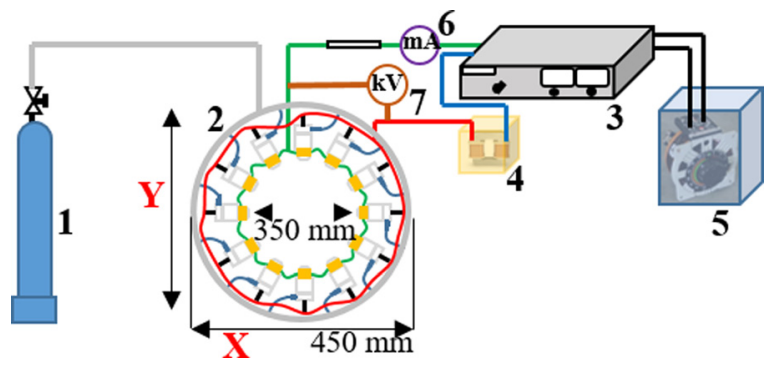

FIG. 1. (Color online) Setup used in this experimental campaign. Where 1 is gas cylinders, 2 is the 12 jet circular system, 3 is the power generator, 4 is the $\mathrm{HV}$ transformer, 5 is the variac, 6 is the current probe, and 7 is the voltage probe.

nozzle. In this work, two noble gases are used as a feed gas: argon and helium. The flow rate was changed from 0.1 to $10.01 \mathrm{~min}^{-1}$. The argon and helium gas velocities, during this experiment, never exceeded $15 \mathrm{~m} \mathrm{~s}^{-1}$ and had a laminar flow with a Reynolds number around 600. Apart from pure argon or helium discharges (ratio 1:0), the design of experiment (DOE) includes noble gas mixtures of up to the ratio of 1:10 (i.e., ten times more argon then helium and vice versa). In order to collect the spatial and temporal optical data by covering the multivariate process space and evaluate the crossdependencies of the measured outputs, a comprehensive 7 factor mixed levels DOE is included. The factors and levels are: gas chemistry ratio with 7 levels $(1: 0,2: 5,1: 10,5: 5,10: 1,5: 2$, $0: 1)$, gas flow rate with four levels $\left(0,3,5,101 \mathrm{~min}^{-1}\right)$, high

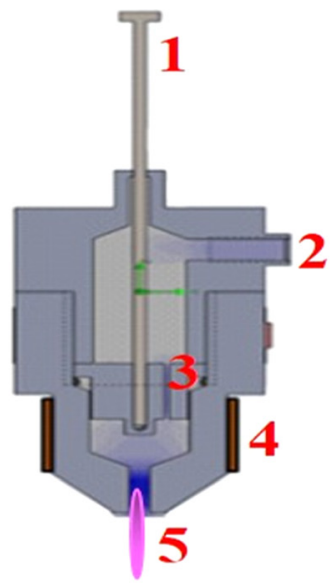

a

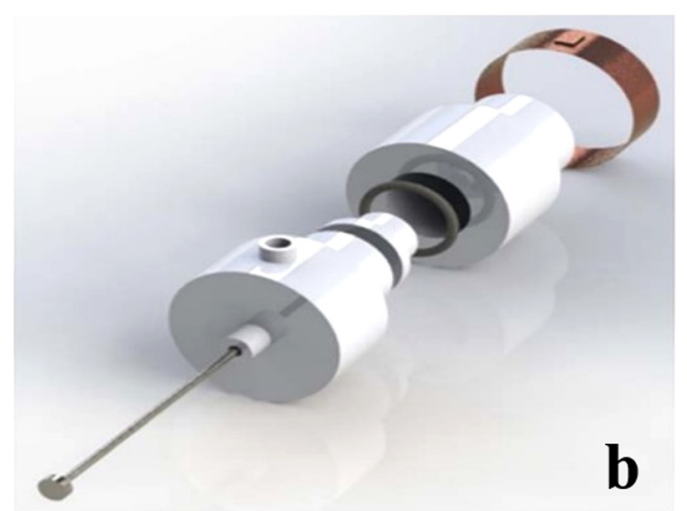

FIG. 2. (Color online) Plasma jet design [(a) schematic and (b) modeling]. Where 1 is the HV electrode, 2 is the gas inlet, 3 is the dielectric barrier, 4 is the ground electrode, and 5 is the plasma jet plume. voltage with four levels $(15.4,22,28,36 \mathrm{kV})$, discharge frequency with five levels $(28,32,35,42,48 \mathrm{kHz})$, duty cycle with four levels $(25 \%, 50 \%, 70 \%, 90 \%)$, distance from the nozzle with six levels $(0,8,12,25,33,50 \mathrm{~mm})$ and processing time with 31 levels (from 0 to $300 \mathrm{~s}$, every $10 \mathrm{~s}$ ). In this work the D-optimal design is generated by an iterative search algorithm which seeks to minimize the covariance of the parameters. This approach resulted in 686 experimental runs, in contrast to the approach without DOE (one factor at a time) that gives a total number of experimental runs of 416640 without repetitions. It is important to stress, for the purpose of the absorption spectroscopy measurements, that the factor of processing time had 46 levels (from 0 to $300 \mathrm{~s}$, every $10 \mathrm{~s}$ during plasma ON phase and from 300 to $450 \mathrm{~s}$, every $10 \mathrm{~s}$ during plasma OFF phase). Oxygen and nitrogen come from the ambient air and are not controlled, but through the approach used in this experimental design their impact can be measured.

The following are the instruments used for optical spectroscopy in this work: Edmund Optics UV-VIS Enhanced Smart CCD Spectrometer, Andor iStar 334T the third generation intensified charge coupled device (ICCD) and B\&W Tek light source BDS130A (Deuterium/Tungsten Light Source). The spectrometer has a linear CCD chipset, with a wavelength range sensitivity of $200-875 \mathrm{~nm}^{29}$ The blaze angle is optimized to maximize efficiency for the wavelength of the used light. The ICCD has a photocathode spectral range between 120 and $1100 \mathrm{~nm}$, an effective active area of CCD $13.3 \times$ $13.3 \mu \mathrm{m}$, a photocathode quantum efficiency up to $50 \%$, minimum optical gate width of $2 \mathrm{~ns}$, and 2D CCD Sensor: 2D CCD with $1024 \times 1024$ pixels. The ICCD gating capabilities are used to precisely isolate useful signal information while preventing unwanted background signals. A function generator is used to trigger the ICCD and a voltage probe signal for synchronization of the ICCD. Together with the ICCD, a selection of optical filters is used. The use of bandpass filters is one of the simplest and most economical ways to transmit a welldefined band of light and to reject unwanted radiation. The optical filters are from Andover corporations with the central wavelengths matched to the recorded plasma emission/absorption lines/bands and with the bandwidth in the range of $0.15-2.0 \mathrm{~nm}$. The BDS130A is a turnkey fiber coupled UV/visible (Vis)/near infrared (NIR) light source with a spectral output from 190 to $2500 \mathrm{~nm}$. The UV/Vis lamp is a $30 \mathrm{~W}$ deuterium lamp providing the advantage of low heat generation and efficient power conversion. A tungsten halogen lamp shares the optical path with the deuterium lamp and provides Vis/NIR emission. The UV/Vis and Vis/NIR light sources can be individually turned on and off. An electronic shutter is included to control the light output using another switch on the front panel. The BDS130A features an SMA 905 connector for fiber optic light coupling with no fiber alignment needed.

The optical techniques are based on the integration of measured signals over a line-of-sight observation. Experiments were carried out to investigate species' spectral intensities with the varying seven external parameters (factors). The processing time, i.e., the time sequence of the recorded spectrum, was every $10 \mathrm{~s}$ for a duration of $3 \mathrm{~min}$ (plasma $\mathrm{ON}$ ), and additional $1.5 \mathrm{~min}$ at plasma OFF (only for OAS). Analyzing the light 
emitted by neutrals, ionized atoms, radicals, and/or molecules is possible by OES. This technique is widely used as a diagnostic tool in plasma processing and it can be used for excited species characterization, photon flux determination as a function of wavelength, for actinometry, and as a diagnostic for electron beams. ${ }^{29}$ A lack of spectral radiation is a problem for emission spectroscopy, in that case absorption spectroscopy may be used. Molecular absorption spectroscopy in the UV/Vis is concerned with the measured absorption of radiation in its passage through a plasma bulk and sheath. For PROES, the ICCD is used, since it is suitable for nanosecond time-resolved imaging. The frequency of the plasma generator is too low with respect to the lifetime of electrons at the excited energy levels. Namely, the generator used in this experimental campaign could be varied over the frequency 28 to $48 \mathrm{kHz}$ to generate plasma, which is equivalent to a time scale from 36 to $21 \mu \mathrm{s}$, respectively. In this type of plasma, the majority lifetimes of electron at excited energy levels are tens of ns, i.e., 1000 times shorter than the duration of the kilo-hertz cycle. Therefore, PROES data will show an average optical signal of individual plasma species and the impact of the duty cycle on that signal.

The important aspect of this work is material selection (conductive and nonconductive). The following list of nonconductive materials has been tested: polyvinylidene fluoride, polyacetal, polyethylene terephthalate, polyethylene ultra high molecular weight, polyamide, polycarbonate, and machinable ceramic. Our selection was acetal, based on the relative permittivity of a material and the electrical breakdown properties.

Figure 2 shows a cross section through the final source design which consists of an acetal cylindrical reactor housing, central stainless steel electrode, brass outer electrode, and acetal dielectric barrier. The inner electrode the high voltage and the outer electrode is grounded. The annular gap between the electrodes is $6 \mathrm{~mm}$.

Twelve dielectric barrier atmospheric pressure plasma jets were arrayed around a polycarbonate cylinder. Gas is distributed through a network of $6 \mathrm{~mm}$ polyfluoroacetate tubing. By developing an effective single plasma jet source and combining them to form a multiaxial source, it is proposed that a complex three dimensional shape can be treated. In addition, a $1 \mathrm{~m}$ long tube with a $350 \mathrm{~mm}$ diameter serves as a reactor tunnel. This configuration facilitates greater retention of the active species due to the semiconfined plasma [Fig. 3(b)] when compared to the open-air plasma [Fig. 3(a)].

\section{RESULTS AND DISCUSSION}

For over more than a decade, plasma jet technology has been used to etch and activate surfaces. In most cases, this process is performed by a single plasma jet device that is either static or mounted on a computer numerical control machine (i.e., XYZ stage or robotic arm) which can be moved. There were also experimental works which include multiple jets in one plate, three or four plasma jet systems that at the same time carry out plasma treatment of some surface. Our work includes 12 plasma jets in a circular geometry sufficiently large for many industrial applications. ${ }^{30}$

For most commercial plasma jet systems, ${ }^{29,31-33}$ the distance between the sample surface and the plasma plume, and the plasma treatment time are critical parameters. In addition, the plasma plume temperature gradient and limited carrier gas chemistry reduce the amount of specific reactive species to interact with the sample surface. There are several atmospheric plasma jet systems used by the scientific community. Most of them are conical and come to a point, ${ }^{29,31,33}$ but there are linear designs which can be seen with the $\mathrm{SurFx}^{32}$ system that has a broad plasma jet (around $50 \mathrm{~mm}$ ). Their common characteristics include a plume which is on the order of centimeters and the diffusion of reactive species rapidly to ambient air. Figure 4 shows a large multijet array designed for continuous treatment of products by employing a conveyor belt and a surrounding tube (tunnel) to help retain the reactive species. A comprehensive, four dimensional $(x, y, z, t)$, optical diagnostic has been employed in order to study any temporal and spatial shift in radical concentrations. In the plain surface (with the 12-jets), it is important to have homogeneity of the radicals' concentration in time and space, which means the
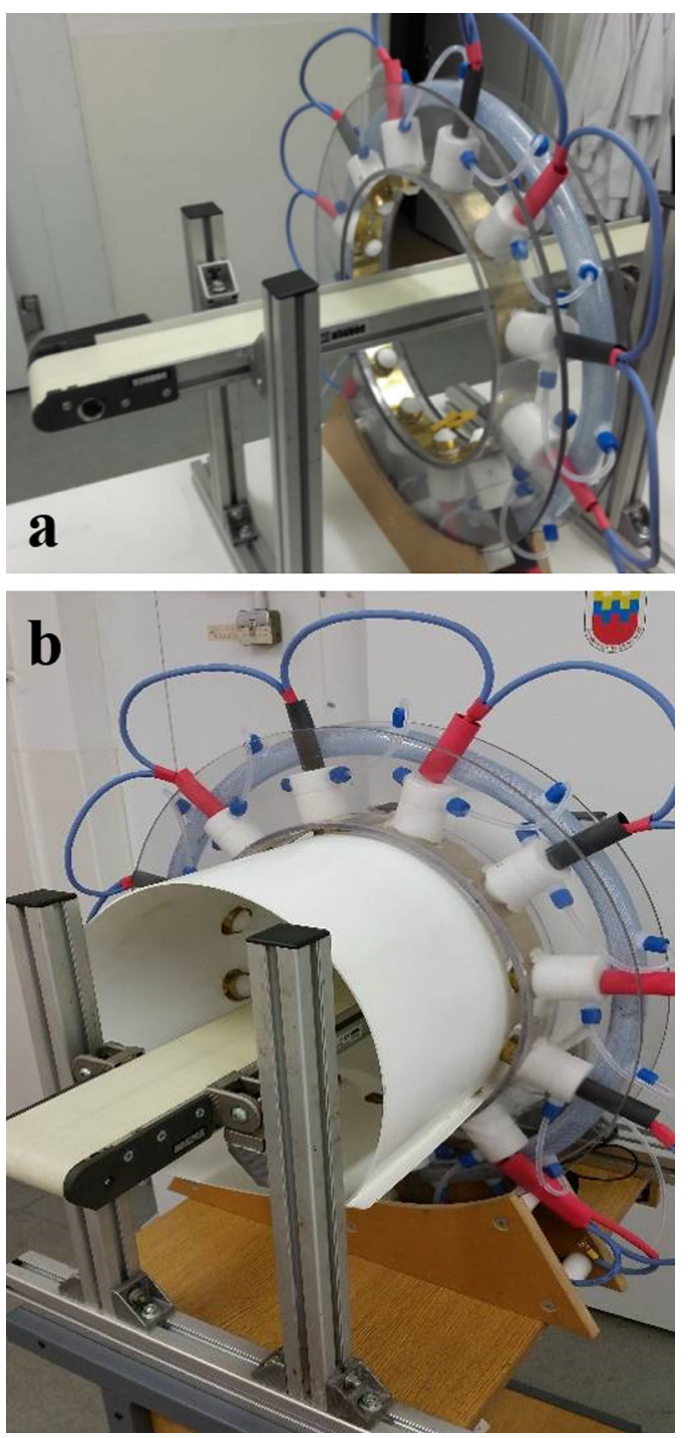

FIG. 3. (Color online) Photographs of the 12-jets system (a) and the 12-jets system and tunnel (b). The belt conveyor system (on the both photographs) has an adjustable speed from minimal $10^{-3} \mathrm{~m} / \mathrm{s}$ to maximal $10^{-2} \mathrm{~m} / \mathrm{s}$, and it is using for a transport of organic and inorganic materials. 
concentration is isotropic around every point. Homogeneity (in space) implies conservation of momentum; and homogeneity in time implies conservation of energy. Therefore, plasma treatment by the 12 -jets system would not significantly depend on the sample's position or treatment time, contrary to other plasma jet technologies. ${ }^{29,31-33}$

In Fig. 5, the total intensity represents a collection of spectral radiation form all species in the plasma. The measurement is performed by using the ICCD with an exposition time of 2 $\mathrm{s}$ for PROES. One approach to compare the intensity among the different experimental conditions is by normalization of the spectral intensity. The normalized intensity for each spectral line from the plasma is a ratio between the current spectral intensity (of that emitter) and a maximum spectral intensity for the given experimental conditions. For Fig. 5, the graphs are normalized and expressed in arbitrary units. This allows for comparison of the total intensity for the 12-jet plasma system, without (left) and with (right) the tunnel. Both graphs show a stable and radially homogenous plasma volume, but the total intensity is about 2.2 times higher for the tunnel system. Single jet systems have a strong radiation density gradient in all directions from the nozzle, however for this design little radiation density fluctuation was observed. Moreover, with the 12-jet and tunnel system there is a radially homogeneous plasma volume. In this work, the design of the jets and the distance among them creates favorable plasma conditions.

For the 12-jet system, argon plasma and the influence of frequency, duty cycle, power, distance, and gas flow rate on
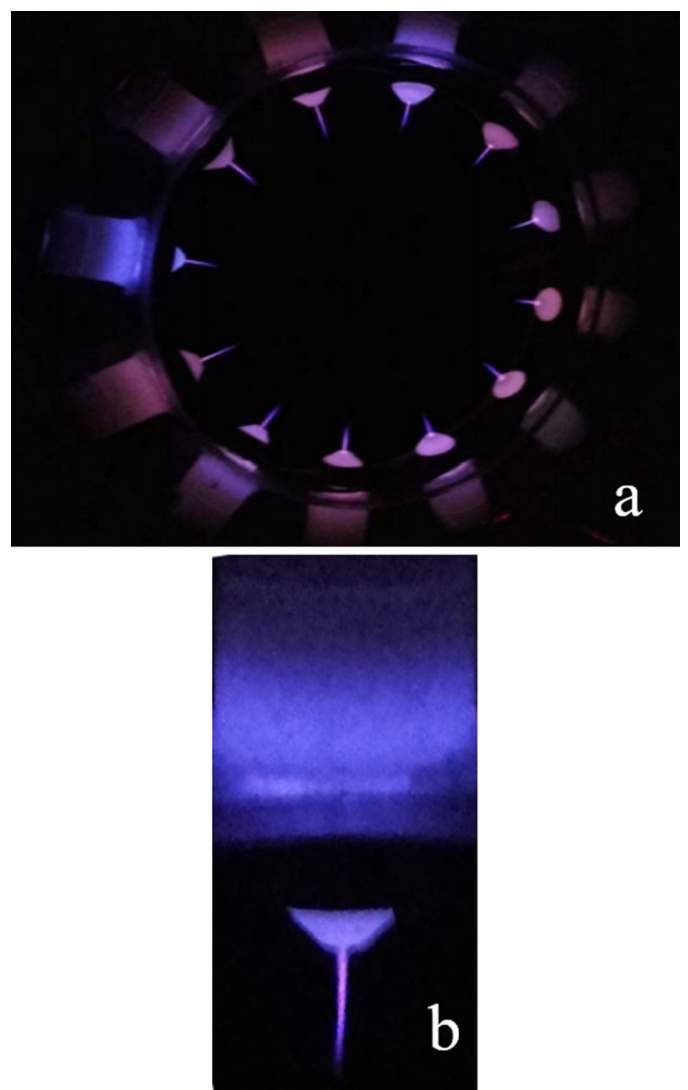

FIG. 4. (Color online) Photographs of the 12 jet system (a) and the single jet system (b). Both photographs include pure helium plasma discharge at gas flow $=31 \mathrm{~min}^{-1}, \mathrm{U}_{\mathrm{HV}}=15.4 \mathrm{kV}, \mathrm{f}=32 \mathrm{kHz}$, and duty cycle $=50 \%$.
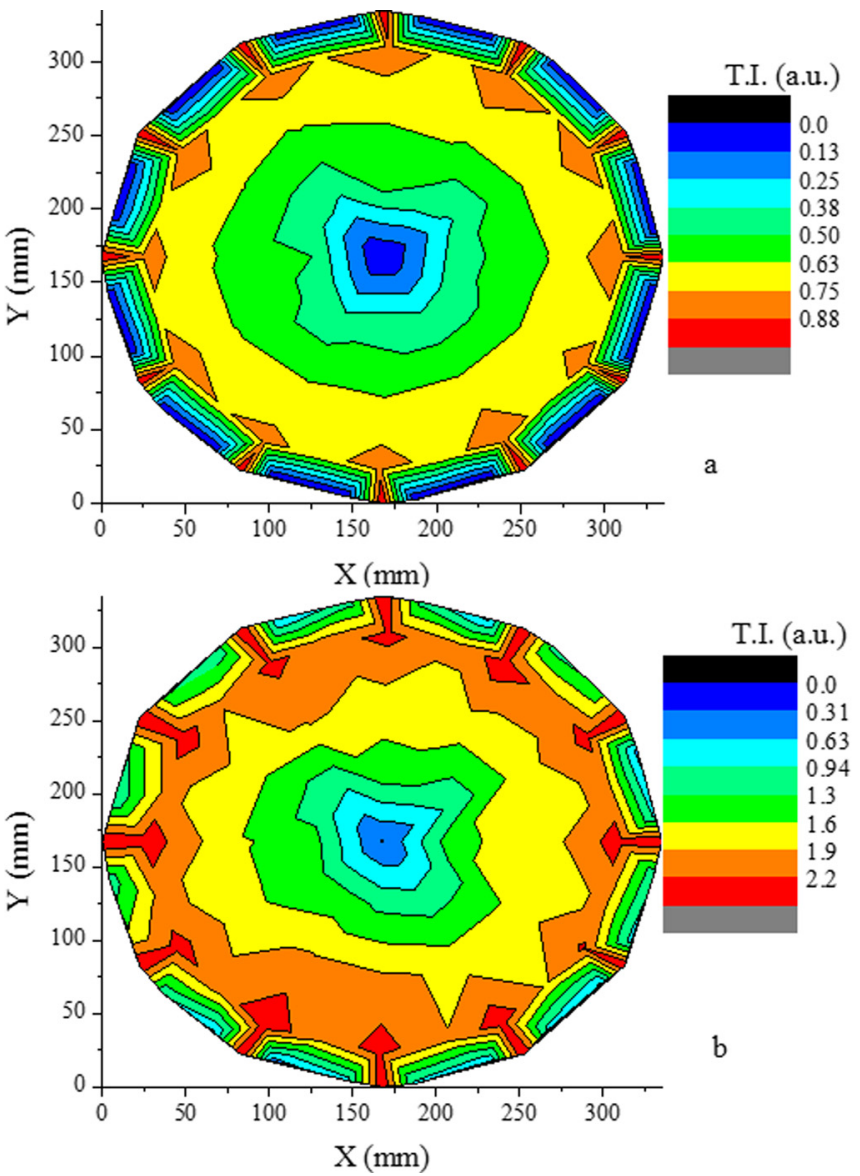

FIG. 5. (Color online) Total intensity (TI in arbitrary units) from the 12-jet system (a) and the 12-jet system and tunnel (b). The both couture graphs include helium-argon mixture at gas chemistry ratio 10:1, helium gas flow $=51 \mathrm{~min}^{-1}, \mathrm{U}_{\mathrm{HV}}=15.4 \mathrm{kV}, \mathrm{f}=28.7 \mathrm{kHz}$, and duty cycle $=90 \%$.

the spectral intensity has been studied. Figure 6 shows the total argon spectral emission of six atomic lines, i.e., (a) intensity as a function of voltage and frequency and (b) intensity as a function of duty cycle and frequency. Argon (4p), oxygen (3p), and nitrogen $\left(\mathrm{C}^{3} \Pi^{+}{ }_{\mathrm{u}}\right)$ excited energy states have very similar energy levels, the difference among them is about 1 $\mathrm{eV} .{ }^{29}$ At atmospheric pressure, plasma kinetics is impacted by quenching of the argon metastable states. ${ }^{29}$ The two argon metastable states have lifetime of tens of second. Therefore, the two maxima for Figs. 6(a) and 6(b) show the optimum external parameters for argon spectral emission. Plasma generated with argon as the primary gas has a maximum emission for the frequency of $42 \mathrm{kHz}, \mathrm{U}_{\mathrm{HV}}$ of $22 \mathrm{kV}$, duty cycle of $70 \%$, and gas flow rate of $51 \mathrm{~min}^{-1}$.

Figure 7 shows the impact of external factors on helium spectral radiation. The helium total spectral intensity (the three helium spectral lines), in pure helium plasma, is linearly changed as a function of: frequency, duty cycle, power, distance, and gas flow rate. For some of these parameters, the change of intensity is quicker, e.g., duty cycle, but for others it is slower, e.g., frequency. Nevertheless, linear changes are a common feature for the dependence of the helium spectral intensity on the external parameters. This is due to the differences in the energy scale of helium and ambient air gases $\left(\mathrm{N}_{2}\right.$, $\mathrm{O}_{2}$, and $\mathrm{CO}_{2}$ ). For this parameter space and electrical design of 

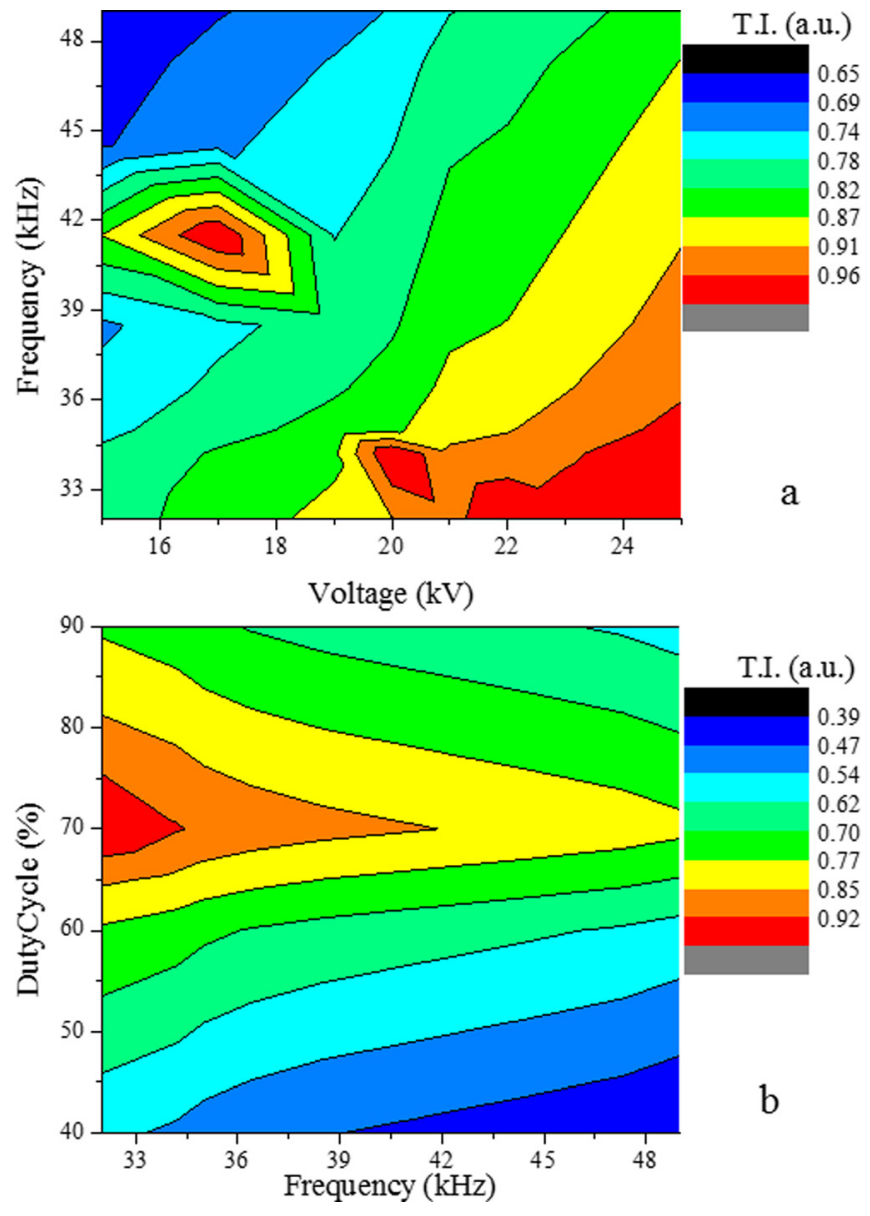

FIG. 6. (Color online) Total argon intensity (TI in arbitrary units) for the 12jet system. The graphs include pure argon gas chemistry, argon gas flow $=5$ $1 \mathrm{~min}^{-1}$, and distance from the jets nozzle $=0 \mathrm{~mm}$. In (a), duty cycle $=70 \%$, and in (b), $\mathrm{U}_{\mathrm{HV}}=22.0 \mathrm{kV}$.

the power source, the plasma system never reaches resonance, i.e., nonradiative energy transfer between helium atom and ambient air molecules. This is opposite to the argon spectral emission and argon plasma (Fig. 6).

The length of the plasma plume is affected by the power source, design of the jet nozzle, and the carrier gas. The interaction between the carrier gas and ambient air is also reflected by the plume length. The plasma plume has a greater stable length (in time and space) for the 12-jet system than the single jet system. The ring jet configuration has 12 individual plasma plumes, and in Fig. 8, the plume length averaged results (from all 12 plasma jets) are presented. There is a linearity for the helium plume with discharge frequency and with the duty cycle (not shown here), but for argon plasma there is a maximum in the plume length. The peak in argon plasma plume length is at $42 \mathrm{kHz}$. Differences between the atomic energy scales of argon and helium plays a significant role in interactions with ambient air species. Namely, a small energy gap between the energy levels of the argon atoms and energy levels of the introduced molecules (from ambient air) energy levels lead to an efficient energy transfer among them.

For plasma-biological applications, oxygen is generally identified the most important of the atmospheric plasma species. In this work, $\mathrm{O}_{2}$ and $\mathrm{O}_{3}$ molecules are observed using

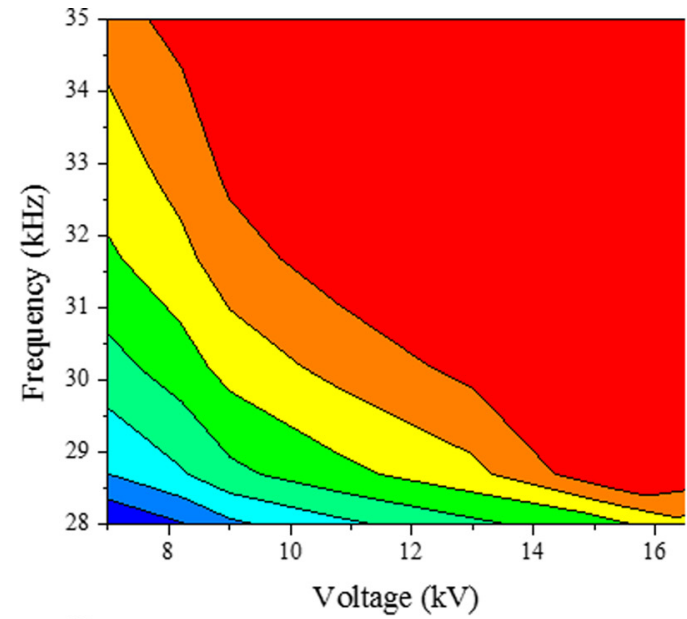

T.I. (a.u.)
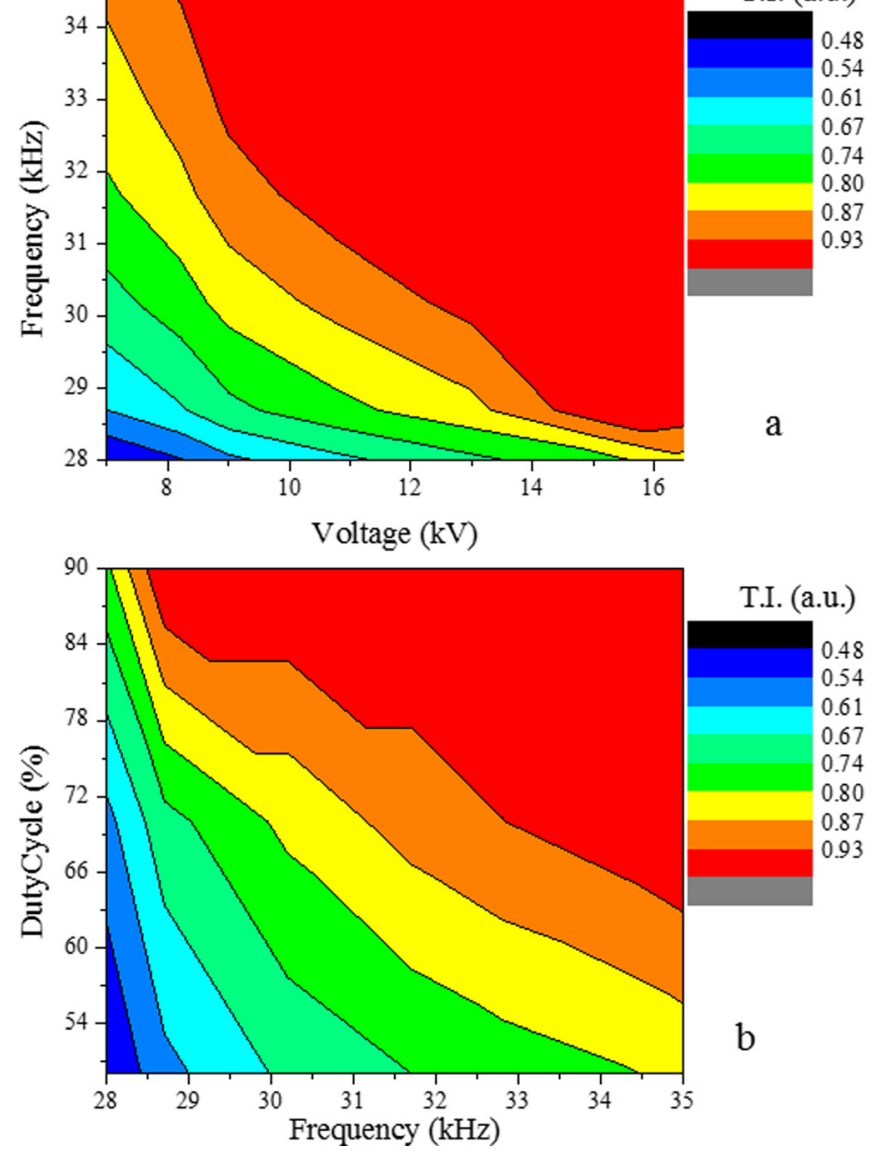

FIG. 7. (Color online) Total helium intensity (TI in arbitrary units) for the 12 -jets system. The graphs include pure helium gas chemistry, helium gas flow $=31 \mathrm{~min}^{-1}$, and distance from the jets nozzle $=0 \mathrm{~mm}$. In (a), duty cycle $=90 \%$, and in (b), $\mathrm{U}_{\mathrm{HV}}=15.4 \mathrm{kV}$.

OAS. The work includes optical absorption results for the 12jet and the single jet systems, representing both plasma on and plasma off time. OAS is performed throughout $5 \mathrm{~min}$ of plasma on time, and an additional $2.5 \mathrm{~min}$ after the plasma discharge was switched off (plasma off time), i.e., $7.5 \mathrm{~min}$ in total. OAS data correction involves a beam splitter which create a separate reference optical signal. ${ }^{26}$ The OAS signal recorded by the spectrometer was used to determine the molecular oxygen densities, based on the Lambert-Beer law [Eq. (1)]. As is well known, the Lambert-Beer gives the relationship between absorbance and concentration of an absorbing species

$$
D(t)=\frac{1}{\sigma(\lambda) \cdot L} \cdot \ln \frac{I(0)}{I(t)} .
$$

Here, $\mathrm{D}(\mathrm{t})$ is the density $\left(\mathrm{cm}^{-3}\right), \mathrm{L}$ is the path length $(\mathrm{cm})$, $\sigma(\lambda=253.7 \mathrm{~nm})=1.154 \times 10^{-17} \mathrm{~cm}^{2}$ and $\sigma(\lambda=760 \mathrm{~nm})$ $=4.94 \times 10^{-23} \mathrm{~cm}^{2}$ are wavelength-dependent absorption cross sections for $\mathrm{O}_{3}$ and $\mathrm{O}_{2}$, respectively, and $\mathrm{I}(0)$ the reference signal intensity at the start $(\mathrm{t}=0)$ when the plasma is off. For $\mathrm{O}_{3}$, the intensity of the Hartley band (at $254 \mathrm{~nm}$ ) is recorded. At the short distance from the nozzle(s), $\mathrm{O}_{3}$ concentrations show similar values (Fig. 9, $5 \mathrm{~mm}$ ). After the power source is turned off, the difference in $\mathrm{O}_{3}$ concentrations at $5 \mathrm{~mm}$ could be observed. That difference is more 


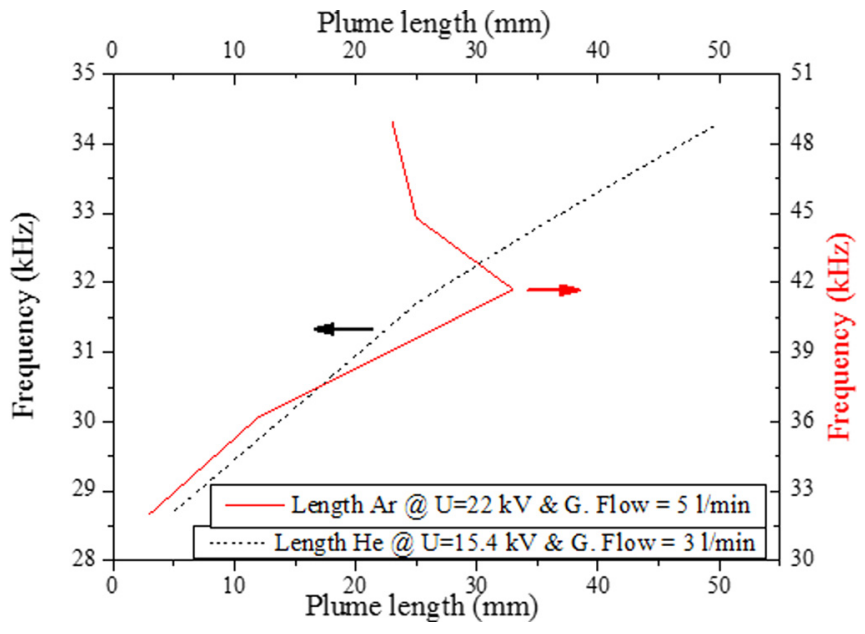

FIG. 8. (Color online) Plasma plume measurements for the 12-jet system as a function of discharge frequency. The red solid line is pure argon plasma discharge, and the black broken line is pure helium plasma discharge.

significant for the ring jet configuration than a regular single jet system. Moreover, at a distance of $100 \mathrm{~mm}$, the $\mathrm{O}_{3}$ concentration is almost ten times higher for the 12-jet system than the 1-jet system. For the plasma off time, the $\mathrm{O}_{3}$ concentration remains almost constant for the 12-jet system. Overall the results point to a stable $\mathrm{O}_{3}$ concentration in both time and space for 12-jet plasma system.

Apart from ozone, $\mathrm{O}_{2}$ plays an important role in the physical and chemical processes of plasma. The oxygen concentration is calculated [Eq. (1)] from the intensity of the $\mathrm{O}_{2}$ A-band (at $760 \mathrm{~nm})$. At $5 \mathrm{~mm}$ from the nozzle(s), there is a greater difference between $\mathrm{O}_{2}$ concentrations between the 12-jet and 1-jet systems (Fig. 10) than observed for the ozone concentrations (Fig. 9). This is due to the size of $\mathrm{O}_{2}$ and $\mathrm{O}_{3}$ molecules, and their associated absorption cross sections values. At $100 \mathrm{~mm}$ from the nozzle(s), the difference in $\mathrm{O}_{2}$ concentration between the two systems is a factor of about 7 , which remains relatively constant for an additional $150 \mathrm{~s}$ (plasma off time). $\mathrm{O}_{2} \mathrm{~b}^{1} \Sigma^{+}{ }_{\mathrm{g}}$ is a metastable state with a low energy and long lifetime; therefore, it can be populated from the ambient air molecules.

Nonequilibrium plasma kinetics play an important role in understanding the chemical reactions occurring under atmospheric plasma conditions. Of particular interest are plasma processes which have a speed that match the time scale of the kilo-hertz power generator cycle. PROES is a technique with that possibility, facilitating in-depth diagnostics. The $\mathrm{N}_{2}$ second positive system, in argon and helium plasma, has been recorded by PROES (Fig. 11). As mentioned previously, there is an energy similarity among argon and nitrogen molecule energy states, but despite that, the recorded $\mathrm{N}_{2}$ intensity is much higher in the helium plasma then in argon (Fig. 11). The helium atom has a huge impact on the population of the $\mathrm{N}_{2}{ }^{+} \mathrm{B}^{2} \Sigma_{\mathrm{u}}$ state, since the energy of this state is very similar to the HeI $2 s^{3} S_{1}$ metastable state. From the $\mathrm{B}^{2} \Sigma_{\mathrm{u}}$ state, through the efficient process of molecular recombination, the $\mathrm{N}_{2} \mathrm{C}^{3} \Pi_{\mathrm{u}}$ state would be populated. Therefore, helium has a significant stepwise impact on the $\mathrm{N}_{2}$ spectral emissions, which is almost linear with the applied duty cycle (and other external parameters not shown

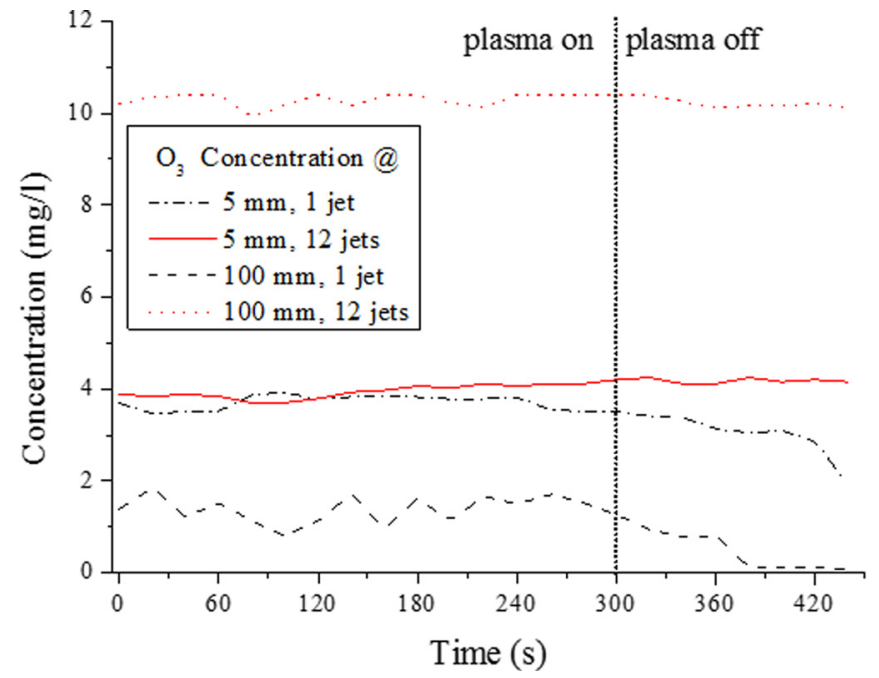

FIG. 9. (Color online) OAS measurement of $\mathrm{O}_{3}$ concentration in a pure argon plasma for the 12-jet system (solid line and dotted line) and 1-jet system (dashed-dotted line and dashed line) as a function of processing time. Argon gas flow is $51 \mathrm{~min}^{-1}$, duty cycle is $70 \%$, and $\mathrm{U}_{\mathrm{HV}}=22.0 \mathrm{kV}$. The dashed-dotted and solid lines are measurements at $5 \mathrm{~mm}$ distance from the jet(s) nozzle, and the dotted and dashed lines are measurements at $100 \mathrm{~mm}$ distance from the jet(s) nozzle. The vertical broken line splits the abscissa axis on two, on the left is 300 s plasma treatment time and on the right is an extra $150 \mathrm{~s}$ with no plasma discharge.

here) and not that sensitive as in the case of argon. That is, for argon the $70 \%$ duty cycle shows a drastic increase (about eight times) in $\mathrm{N}_{2}$ intensity over the operation at the $25 \%$ duty cycle. Also for argon plasma, the $\mathrm{N}_{2}$ spectral intensity shows much more sensitivity to switching the electric field from on to off (the black lines' slope at $25 \%$ and $70 \%$ DC), due to a direct impact from argon to molecular nitrogen excited energy states.

For atomic oxygen, PROES is presented in Fig. 12. Oxygen spectral emission records a higher intensity for argon than

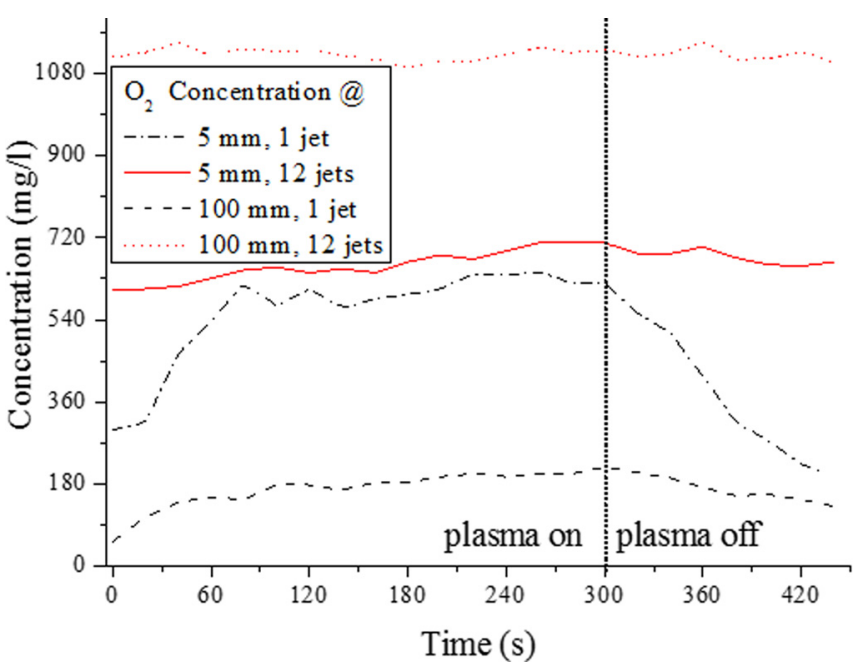

FIG. 10. (Color online) OAS measurement of $\mathrm{O}_{2}$ concentration in a pure argon plasma for the 12-jet system (solid line and dotted line) and 1-jet system (dashed-dotted line and dashed line) as a function of processing time. Argon gas flow is $51 \mathrm{~min}^{-1}$, duty cycle is $70 \%$, and $\mathrm{U}_{\mathrm{HV}}=22.0 \mathrm{kV}$. The dashed-dotted and solid lines are measurement at $5 \mathrm{~mm}$ distance from the jet(s) nozzle, and the dashed and dotted lines are measurement at $100 \mathrm{~mm}$ distance from the jet(s) nozzle. The vertical broken line splits the abscissa axis on two, on the left is $300 \mathrm{~s}$ plasma treatment time, and on the right is an extra $150 \mathrm{~s}$ with no plasma discharge. 
helium plasma due to a difference in the mechanisms of population of the ${ }^{5} \mathrm{P}$ oxygen state and the mismatch in energy of the excited argon and oxygen states ${ }^{29}$ and helium and oxygen states. ${ }^{34}$ The energy of the ${ }^{5} \mathrm{P}$ level and argon $4 \mathrm{p}$ state are very similar, and the influence of the high oxygen excited energy levels $(5 \mathrm{~s}, 6 \mathrm{~s}$, and $4 \mathrm{~d})$ to population of the ${ }^{5} \mathrm{P}$ state can be neglected (lacking of spectral emissions from the high-lying excited energy levels of atomic oxygen atom). Figure 12 shows a slow decrease in the oxygen intensity emission with the switching of the electric field (on/off) for the argon plasma and rapid response for argon plasma. This shows again the importance of argon excited atoms for population of oxygen exited levels.

To assess our plasma system we compare its performance against similar, well characterized atmospheric jets. The four commercial plasma jet systems selected are well documented in the literature in terms of mechanisms, efficacy, and applications. Our system is compared with PlasmaStream ${ }^{\mathrm{TM}}, 31$ KinPen $^{\text {TM }}{ }^{29}$ SurFx Atomflo ${ }^{\text {TM }} 32$ and PlasmaPen ${ }^{\text {TM }}$ PVA. ${ }^{33}$ Figure 13 shows the absolute spectral intensity [Eq. (2)] of $\mathrm{N}_{2}, \mathrm{~N}_{2}{ }^{+}, \mathrm{OH}$, and $\mathrm{O}$ I for seven different jets/systems. This figure also includes the respective intensity fluctuations for $60 \mathrm{~s}$ of treatment time. Overall, the PlasmaPen has the highest intensity fluctuation for all spectral emissions, due to high gas flow rate, high gas pressure and low AC source frequency. ${ }^{33}$ The 12-jet tunnel system has very stable spectral radiation for all four species and also the highest intensity. The design of the tunnel system offers the possibility for more efficient treatments of surfaces (organic or inorganic)

$$
I_{\lambda}^{\text {Spec }}=I_{\lambda}^{\text {Sour }} \cdot \Omega_{\mathrm{eff}} \cdot \Delta A \cdot \Delta \lambda \cdot T_{F} \cdot \frac{\lambda}{h \cdot c} \cdot T_{W} \cdot Q_{\lambda} .
$$

The absolute intensity measured by a spectrometer $\left(I_{\lambda}^{\mathrm{Spec}}\right)$ is dependent on the wavelength $(\lambda)$, and is given by Eq. (2), where $I_{\lambda}{ }^{\text {Sour }}$ is intensity of the light source dependent of the wavelength, $\Omega_{\text {eff }}$ is the effective spatial angle, $\Delta A$ is the effective area of the source, $\Delta \lambda$ is the spectral interval, $T_{F}$ is transparency of the

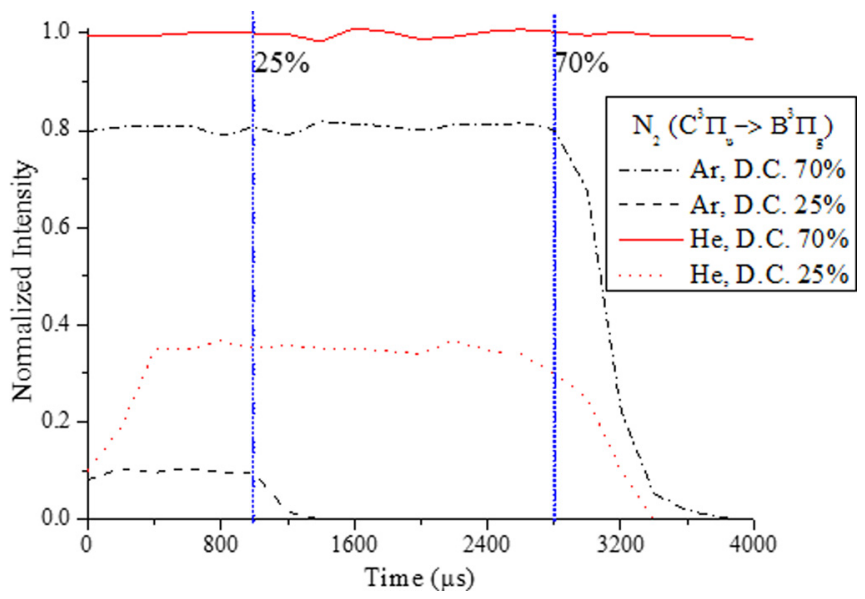

FIG. 11. (Color online) PROES measurements of $\mathrm{N}_{2}$ spectral emission for the 12 -jet system in the respect the plasma source kilo-hertz cycle duration and the duty cycle (DC). The dashed-dotted line and dashed line represents pure argon gas chemistry; and solid line and dotted line are pure helium gas chemistry. For helium plasma: the gas flow rate is $31 \mathrm{~min}^{-1}$, and $U_{\mathrm{HV}}$ is $15.4 \mathrm{kV}$. For argon plasma: the gas flow rate is $51 \mathrm{~min}^{-1}$, and $\mathrm{U}_{\mathrm{HV}}$ is $22.0 \mathrm{kV}$. For both plasmas distance from the jets nozzle is $0 \mathrm{~mm}$. The two vertical broken lines mark the moment of operation of $25 \%$ and $70 \%$ of the duty cycle.

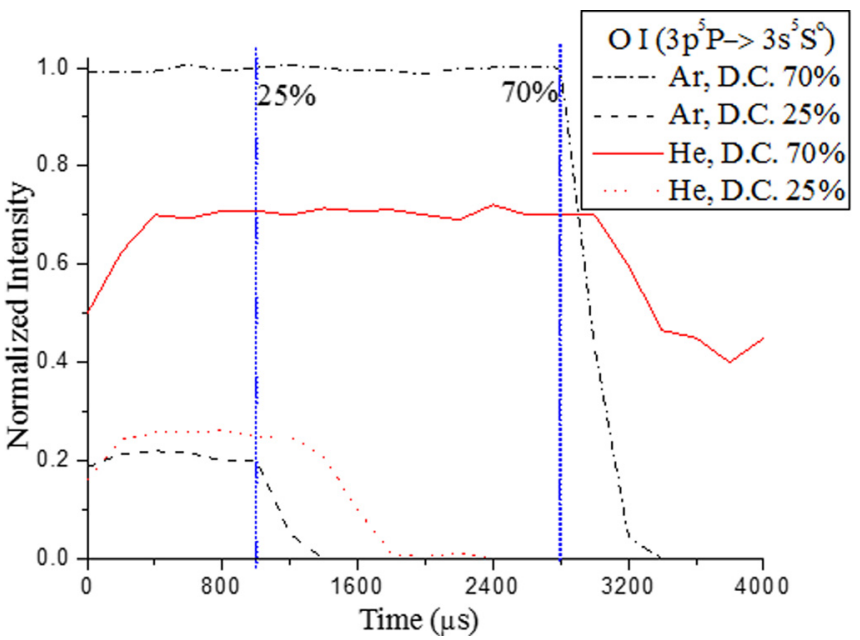

FIG. 12. (Color online) PROES measurements of O I spectral emission for the 12-jet system as a function of kilo-hertz cycle duration and the duty cycle (DC). The dashed-dotted line and dashed line represents pure argon gas chemistry; and solid line and dotted line are pure helium gas chemistry. For helium plasma: the gas flow rate is $31 \mathrm{~min}^{-1}$, and $\mathrm{U}_{\mathrm{HV}}$ is $15.4 \mathrm{kV}$. For argon plasma: the gas flow rate is $51 \mathrm{~min}^{-1}$, and $\mathrm{U}_{\mathrm{HV}}$ is $22.0 \mathrm{kV}$. For both plasmas, the distance from the jets nozzle is $0 \mathrm{~mm}$. The two vertical broken lines marks the moment at $25 \%$ and $70 \%$ of the duty cycle.

interference filter, $T_{W}$ is transparency of the window on light source, and $Q_{\lambda}$ is the quantum efficiency of the spectrometer.

The EEDF is an important plasma characteristic. EEDF drives the plasma kinetics in all jet systems. Some spectral lines are created by direct electron excitation from the ground level and their spectral intensity is sensitive to the high-energy electron portion of the EEDF. The intensity for some other spectral lines are sensitive to low-energy electrons. Therefore, a change in the ratio between those two set of spectral emissions indicates the change in the EEDF. In this work, the EEDF is recovered through the argon spectral lines ${ }^{29}$ and nitrogen spectral emission. ${ }^{26}$ The $\mathrm{N}_{2}{ }^{+} 391$ spectral emission is created by direct electron excitation from the ground level and is sensitive to the high-energy electron portion of the EEDF; conversely, the production of the $\mathrm{N}_{2} 337$ line is sensitive to low-energy electrons. The relative populations of the two vibronic levels, measured by emission spectroscopy, are related to the EEDF. Therefore, a change in the ratio between $\mathrm{N}_{2} 337$ and $\mathrm{N}_{2}{ }^{+} 391$ spectral emissions indicates the change in the EEDF. A similar change was observed in the argon plasma over Ar750 and Ar811 spectral emissions. Between 5 and $50 \mathrm{~mm}$ from the jets nozzle, the EEDF for the argon plasma is changed: $67 \%$ for the 1 -jet system, $30 \%$ for 12 -jet system and $13 \%$ for the tunnel system. This result shows the advantage of using the tunnel system, not just for chemical production (Fig. 13), but also for the plasma's physical properties.

\section{CONCLUSIONS}

This work employs plasma diagnostic techniques to characterize the plasma discharge from atmospheric plasma jets and quantify the resultant metastable active species and radicals generated by the plasma afterglow/bulk. The study established the influence of gas chemistry and plasma processing parameters on the residence time of plasma reactive 

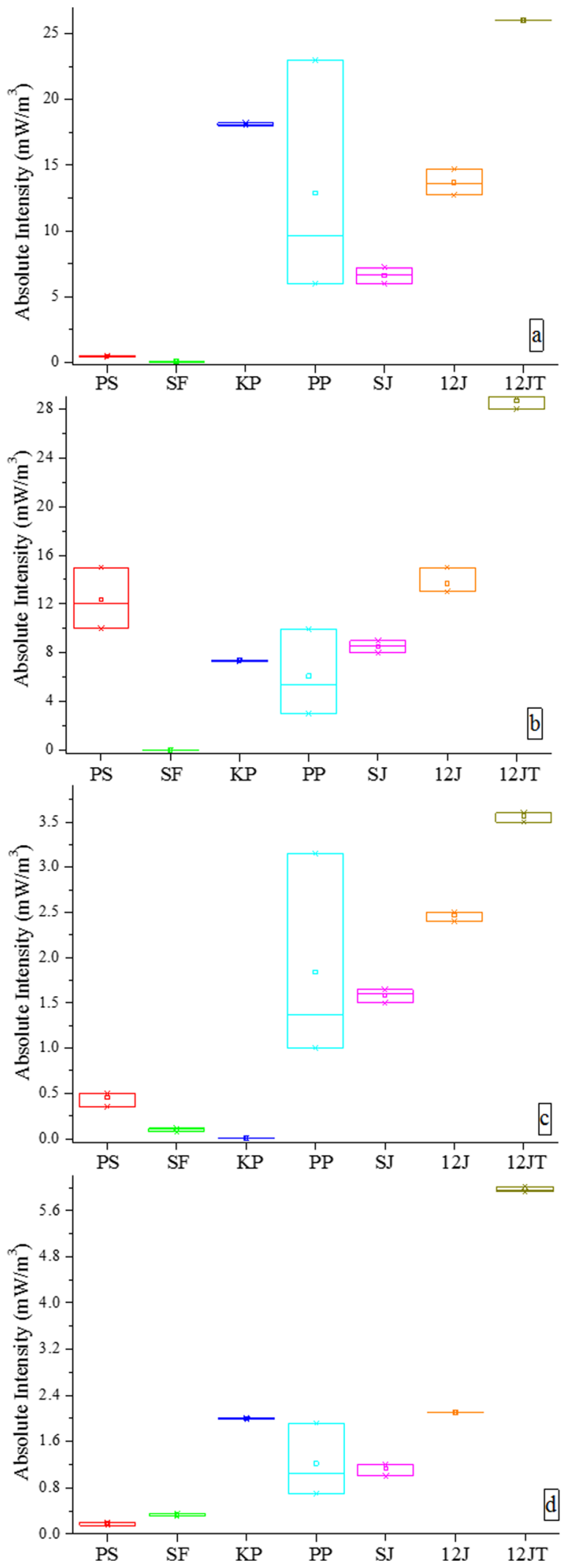

FIG. 13. (Color online) These graphs represent: 4 commercial plasma jet systems (PS, PlasmaStream; SF, SurFx; KP, KinPen; and PP, PlasmaPen), as well as our (in house) 1-jet (SJ), our 12-jet system (12J) and our 12-jet plus tunnel system (12JT). Results shows fluctuation of the total intensity over processing time (up to $60 \mathrm{~s}$ ), at the nozzle level and at the maximum power (different for each system), for: (a) $\mathrm{N}_{2}$ at $337 \mathrm{~nm}$, (b) $\mathrm{N}_{2}{ }^{+}$at $391 \mathrm{~nm}$, (c) $\mathrm{OH}$ at $307 \mathrm{~nm}$ and (d) O I at $777 \mathrm{~nm}$. The gas chemistry for all seven jet systems is helium or argon. species, as well as, the temporal and spatial plasma chemistry dynamics in a single, 12 -jet, and 12-jet semiconfined tunnel system. From the tested materials, the plasma jet made from acetal show the highest durability. The 12-jet plasma system in a circular geometry created a large volume of plasma that could be used for real industrial applications. The duration of plasma processing time and distance from the nozzles, for the 12-jet system is less significant than for other plasma jet systems.

We report a nonradiative energy transfer among the different plasma species which occurs in the nozzle of the jet or in the surrounding atmosphere. The work identifies the link between oxygen and nitrogen reactive species and external processing parameters and geometry. This offers the possibility of plasma source optimization and the development of a better understanding of the impact of a multivariable parameter space on process efficacy. Optical spectroscopy carried out in this work presents the possibility of real-time model-based control of plasma processing systems based on a phenomenological physics model of the nonlinear coupling between the independent controls and the dependent variables of the plasma.

PROES shows a high level of sensitivity for kinetic processes in argon plasma. Ambient air species are more affected by argon than helium, due to the design of the power source and similarity in the energy scales. Oxygen reactive species have much higher concentrations, longer residence times and less spatial and time fluctuations, for the tunnel system than for the other comparable plasma jet technologies.

\section{ACKNOWLEDGMENTS}

This work was funded by the Irish Department of Agriculture, Food and the Marine, Ireland, under the Food Institutional Research Measure (FIRM) initiative (InnoFresh project-Innovative process technologies for the fresh produce industry; Reference No. 13F444). The authors are grateful to Hannah Currivan for technical assistance.

\section{APPENDIX}

For the purposes of this work, the power generator is customized (Fig. 14). The original design of the power source was used for hydrogen and chemical production corona cell with maximum power of $1 \mathrm{~kW}, 25 \mathrm{kV}$ output voltage, and frequency range $15-25 \mathrm{kHz}$.

Over the process of power generator customization, the half bridge architecture has to be replaced with the full bridge. The half bridge has only $1 / 2$ the voltage swing of a full bridge and the half bridge is not suitable for current mode control (which is essential for plasma discharges), as it will walk the center point to one rail or the other. The original maximum of $200 \mathrm{pF}$ capacitor and around $25 \mathrm{kHz}$ frequency was too low for our application and since the target circuit must be resonant, to get an effect of voltage rise, the frequency can be increased to $100 \mathrm{kHz}$ and the load up to 20 $\mathrm{nF}$. That was very important change since the plasma systems have capacitive coupling electrodes with capacitance up to a few nanofarad. 

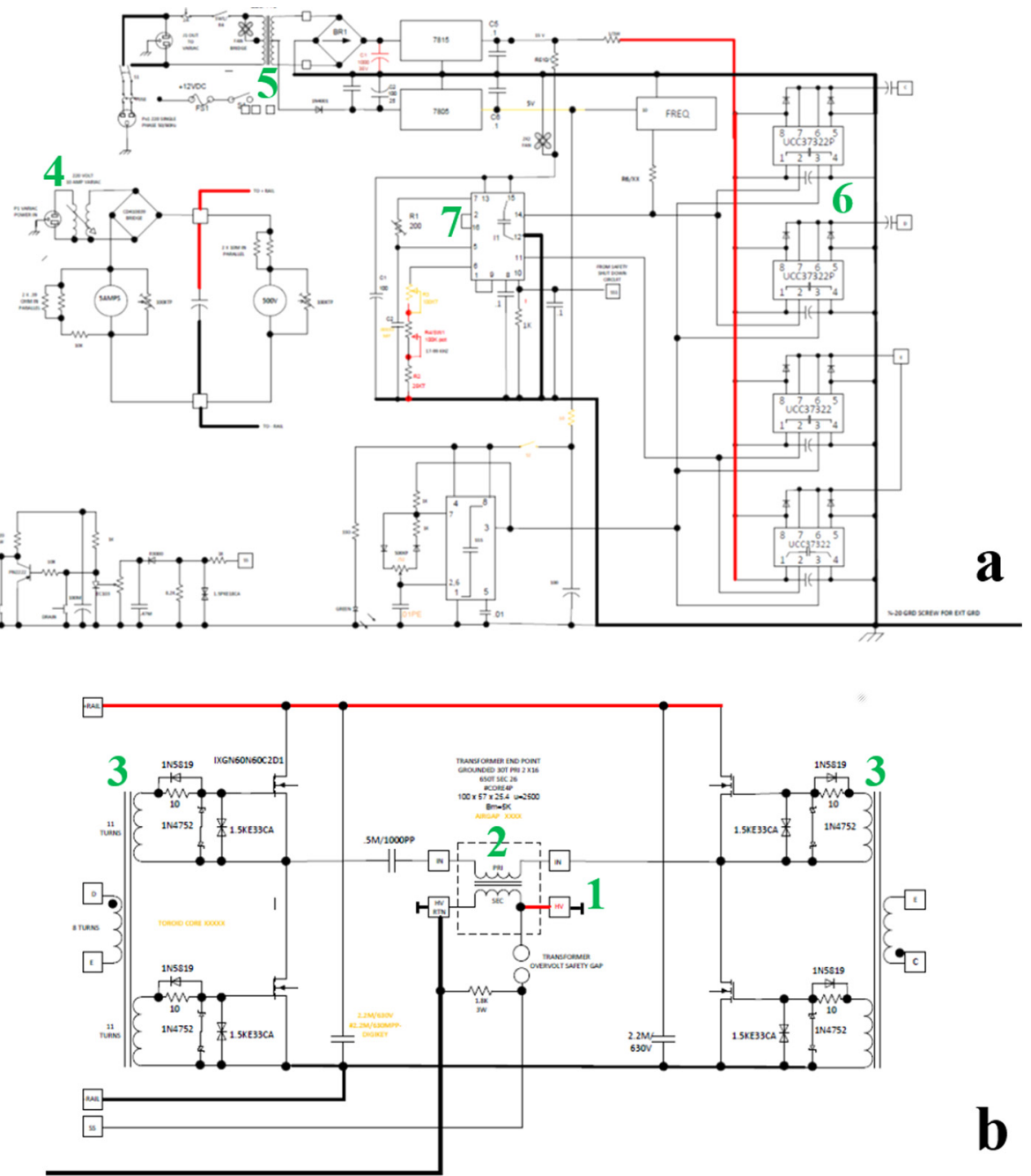

b

FIG. 14. (Color online) Circuit diagram of the power generator. Where 1 is connection to the electrodes, 2 is the oil field HV transformer, 3 is the full bridge converter (four switches and drivers), 4 is the variac, 5 is the rectifier (a diode used for converting AC into DC output) or Off-line converter, 6 is four drivers, and 7 is the unit that control/define the circuit frequency.

A photograph of the power generator [schematic Fig. 14(a)] is presented in Fig. 15. This is an open source system and not, as in the most cases, a closed-box design with the plasma generator housed in the close unit, and consequently limiting plasma diagnostics.

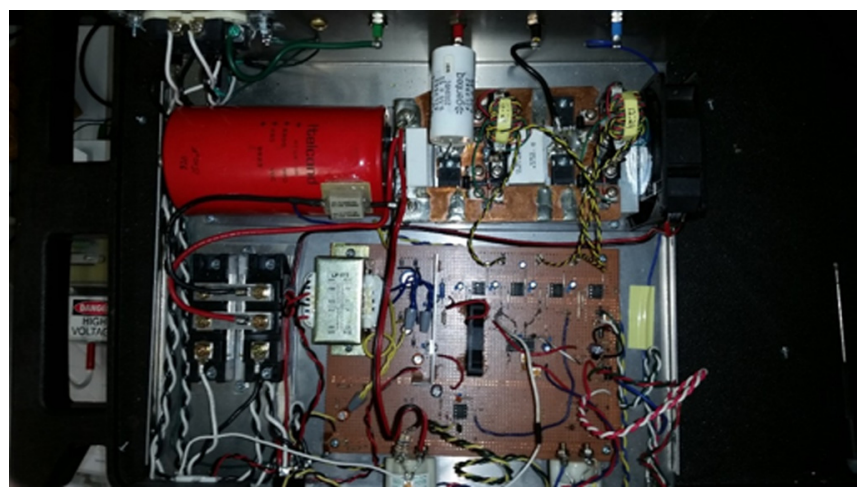

FIG. 15. (Color online) Top view of the power generator.
${ }^{1}$ K. Inomata, N. Aoki, and H. Koinuma, Jpn. J. Appl. Phys., Part 2 33, L197 (1994).

${ }^{2}$ J. Park, I. Henins, H. W. Herrmann, G. S. Selwyn, J. Y. Jeong, R. F. Hicks, D. Shim, and C. S. Chang, Appl. Phys. Lett. 76, 288 (2000).

${ }^{3}$ H. M. Abourayana, V. Milosavljević, P. Dobbyn, P. J. Cullen, and D. P. Dowling, Surf. Coat. Tech. 308, 435 (2016).

${ }^{4}$ H. Hirai, R. Sasaki, T. Takamatsu, M. Shibata, M. Ichikawa, H. Miyahara, and A. Okino, Proceedings of the 63rd 45 Annual Gaseous Electronics Conference and 7th International Conference on Reactive Plasmas (2010), p. 38.

${ }^{5}$ X. Lu, M. Laroussi, and V. Puech, Plasma Sources Sci. Technol. 21, 034005 (2012).

${ }^{6}$ Z. Cao, Q. Nie, D. L. Bayliss, J. L. Walsh, C. S. Ren, D. Z. Wang, and M. G. Kong, Plasma Sources Sci. Technol. 19, 025003 (2010).

${ }^{7}$ N. O'Connor, H. Humphreys, and S. Daniels, IEEE Trans. Plasma Sci. 42, 756 (2014).

${ }^{8}$ J. L. Walsh and M. G. Kong, Appl. Phys. Lett. 93, 111501 (2008).

${ }^{9}$ H. Koinuma, H. Ohkubo, T. Hashimoto, K. Inomata, T. Shiraishi, A. Miyanaga, and S. Hayashi, Appl. Phys. Lett. 60, 816 (1992).

${ }^{10}$ I. E. Kieft, E. P. v d. Laan, and E. Stoffels, New J. Phys. 6, 149 (2004).

${ }^{11}$ M. Teschke, J. Kedzierski, E. G. Finantu-Dinu, D. Korzec, and J. Engemann, IEEE Trans. Plasma Sci. 33, 310 (2005).

${ }^{12}$ X. Lu, Z. Jiang, Q. Xiong, Z. Tang, and Y. Pan, Appl. Phys. Lett. 92, 151504 (2008).

${ }^{13}$ X. Lu, G. V. Naidis, M. Laroussi, S. Reuter, D. B. Graves, and K. Ostrikov, Phys. Rep. 630, 1 (2016). 
${ }^{14}$ T. Murakami, K. Niemi, T. Gans, D. O’Connell, and W. G. Graham, Plasma Sources Sci. Technol. 22, 015003 (2013).

${ }^{15}$ K. Takeda, T. Kumakura, K. Ishikawa, H. Tanaka, M. Sekine, and M. Hori, Appl. Phys. Express 10, 36201 (2017).

${ }^{16}$ J.-S. Oh, O. T. Olabanji, C. Hale, R. Mariani, K. Kontis, and J. W. Bradley, J. Phys. D: Appl. Phys. 44, 155206 (2011).

${ }^{17}$ N. Jiang, J. L. Yang, F. He, and Z. X. Cao, J. Appl. Phys. 109, 093305 (2011).

${ }^{18}$ M. Ghasemi, P. Olszewski, J. W. Bradley, and J. L. Walsh, J. Phys. D: Appl. Phys. 46, 52001 (2013).

${ }^{19}$ X. J. Shao, Z. S. Chang, H. B. Mu, W.-L. Liao, and G.-J. Zhang, IEEE Trans. Plasma Sci. 41, 899 (2013).

${ }^{20}$ E. Karakas, M. Koklu, and M. Laroussi, J. Phys. D: Appl. Phys. 43, 155202 (2010).

${ }^{21}$ T. Darny, E. Robert, D. Ries, S. Dozias, and J. M. Pouvesle, IEEE Trans. Plasma Sci. 42, 2504 (2014).

${ }^{22}$ Y. B. Xian, M. H. Qaisrani, Y. F. Yue, and X. P. Lu, Phys. Plasmas 23, 103509 (2016).

${ }^{23}$ F. Iza, G. J. Kim, S. M. Lee, J. K. Lee, J. L. Walsh, Y. T. Zhang, and M. G. Kong, Plasma Processes Polym. 5, 322 (2008).

${ }^{24}$ G. Y. Park, S. J. Park, M. Y. Choi, I. G. Koo, J. H. Byun, J. W. Hong, J. Y. Sim, G. J. Collins, and J. K. Lee, Plasma Sources Sci. Technol. 21, 043001 (2012).
${ }^{25}$ J. Ehlbeck, U. Schnabel, M. Polak, J. Winter, T. von Woedtke, R. Brandenburg, T. Von, D. Hagen, and K.-D. Weltmann, J. Phys. D: Appl. Phys. 44, 13002 (2011).

${ }^{26}$ V. Milosavljević and P. J. Cullen, Eur. Phys. J. Appl. Phys. 80, 20801 (2017).

${ }^{27}$ A. Kramida, Yu. Ralchenko, J. Reader, and NIST ASD Team, "NIST atomic spectra database (version 5.5.1)," 2018, https://physics.nist.gov/ asd.

${ }^{28}$ G. Herzberg, Molecular Spectra and Molecular Structure (Van Nostrand, New York, 1963), Vol. 1.

${ }^{29}$ P. J. Cullen and V. Milosavljević, Prog. Theor. Exp. Phys. 2015, $063 J 01$ (2015).

${ }^{30}$ P. J. Cullen, J. Lalor, L. Scally, D. Boehm, V. Milosavljević, P. Bourke, and K. Keener, Plasma Processes Polym. 2017, e1700085.

${ }^{31}$ C. E. Nwankire, V. J. Law, A. Nindrayog, B. Twomey, K. Niemi, V. Milosavljević, W. G. Graham, and D. P. Dowling, Plasma Chem. Plasma Process. 30, 537 (2010).

${ }^{32}$ M. Donegan, V. Milosavljević, and D. P. Dowling, Plasma Chem. Plasma Process. 33, 941 (2013).

${ }^{33}$ L. Scally, J. Lalor, P. J. Cullen, and V. Milosavljević, J. Vac. Sci. Technol., A 35, 03E105 (2017).

${ }^{34}$ V. Milosavljević, M. Donegan, P. J. Cullen, and D. P. Dowling, J. Phys. Soc. Jpn. 83, 014501 (2014). 